\title{
RADIOCARBON DATING OF SINGLE COMPOUNDS ISOLATED FROM POTTERY COOKING VESSEL RESIDUES
}

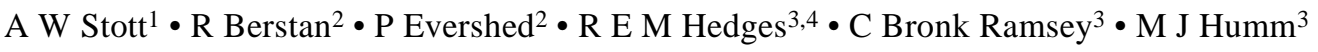 \\ ABSTRACT. We have developed and demonstrated a practical methodology for dating specific compounds (and octade- \\ canoic or stearic acid- $\mathrm{C}_{18: 0}$-in particular) from the lipid material surviving in archaeological cooking pots. Such com- \\ pounds may be extracted from about $10 \mathrm{~g}$ of cooking potsherd, and, after derivatization, can be purified by gas \\ chromatography. To obtain sufficient material for precise dating repetitive, accumulating, GC separation is necessary. \\ Throughout the 6000-year period studied, and over a variety of site environments within England, dates on $\mathrm{C}_{18: 0}$ show no \\ apparent systematic error, but do have a greater variability than can be explained by the errors due to the separation chemistry \\ and measurement process alone. This variability is as yet unexplained. Dates on $\mathrm{C}_{16: 0}$ show greater variability and a systematic \\ error of approximately 100-150 years too young, and it is possible that this is due to contamination from the burial environ- \\ ment. Further work should clarify this.
}

\section{INTRODUCTION}

A common difficulty in dating by radiocarbon is the presence of carbon originating from different sources, with different ${ }^{14} \mathrm{C}$ compositions, in the material chosen for measurement. A powerful aid to selecting material containing carbon from a single and appropriate source is the ability to separate and purify single chemical compounds, which in turn depends on the ability to measure the ${ }^{14} \mathrm{C}$ content of sub-milligram samples using accelerator mass spectrometry (AMS). In this paper we describe a method, together with the results obtained, which is applicable to archaeological potsherds.

Pottery is a good example of chronologically important material which is liable to contain carbon derived from sources of different age. These can include residual geological organic material in the clay remaining after firing, incorporated organic temper, smoke and condensed volatiles during firing, organic material such as food residues remaining from the period of use, and organic material such as humic substances taken up during burial. Some post-depositional chemical change to most of these sources can also be expected. Approaches to the ${ }^{14} \mathrm{C}$ dating of pottery have, therefore, attempted separations of these sources by a variety of methods (Johnson et al. 1986; Evin et al. 1989; Hedges et al. 1992; Kolic 1995); but distinctions, either of chemical composition or of source, have not usually been very clear, and results are liable to be inconclusive.

The chronological importance of pottery is mainly due both to its durability in the archaeological record, and its ability to retain cultural information. Many archaeological cultures are defined in terms of a predominant pattern of ceramic types, forms, or decoration. Indeed the general term "neolithic" is very nearly synonymous with pottery occurrence (despite the recognition of a "Pre-Pottery Neolithic" or of a pottery using Mesolithic). Therefore a date on pottery is generally a direct date on the use of culturally significant material. This is especially useful when contextual information is lacking, Furthermore, because unique pottery styles are often used as chronological markers across sites, the direct dating of potsherds can help confirm or extend this practice. Also, pottery may be the only available dateable organic material from a site, especially where most organic material is lost.

This work builds on developments in gas chromatographic separation which enable sub-milligram quantities of carbon to be purified from complex volatile organic mixtures with an analytical preci-

\footnotetext{
${ }^{1}$ Institute of Terrestrial Ecology, Merelwood, Cumbria, United Kingdom

${ }^{2}$ Department of Chemistry, University of Bristol, Bristol, BS8 1TS, United Kingdom

${ }^{3}$ Research Laboratory for Archaeology, University of Oxford, Keble Road, Oxford, OX1 3QJ, United Kingdom

${ }^{4}$ Corresponding author. Email: robert.hedges@ @laha.ox.ac.uk.
}

(c) 2001 by the Arizona Board of Regents on behalf of the University of Arizona RADIOCARBON, Vol 43, Nr 2A, 2001, p 191-197

Proceedings of the 17 th International ${ }^{14} \mathrm{C}$ Conference, edited by I Carmi and $\mathrm{E}$ Boaretto 
sion, and subsequently dated (Eglinton et al. 1996). It also builds on a sound knowledge of the occurrence of lipids in archaeological potsherds and their burial environments (Evershed et al. 1992, 1999). While bulk lipid extracts from pots have been dated before, the mix of numerous compounds involved prevents easy estimation of the extent of contribution from soil and/or microbes.

We have extracted and then measured the ${ }^{14} \mathrm{C}$ content of the most abundant lipids found in potsherds presumed to be used for cooking, namely the $\mathrm{C}_{18}$ and $\mathrm{C}_{16}$ fatty acids (octadecanoic or stearic acid and hexadecanoic or palmitice acid) and the $\mathrm{C}_{18: 1}$ unsaturated acid (octadecanoic acid). Other compounds are not sufficiently abundant to provide adequate precision for ${ }^{14} \mathrm{C}$ dating unless enormous quantities of sherds are available (see Figures 1 and 2).

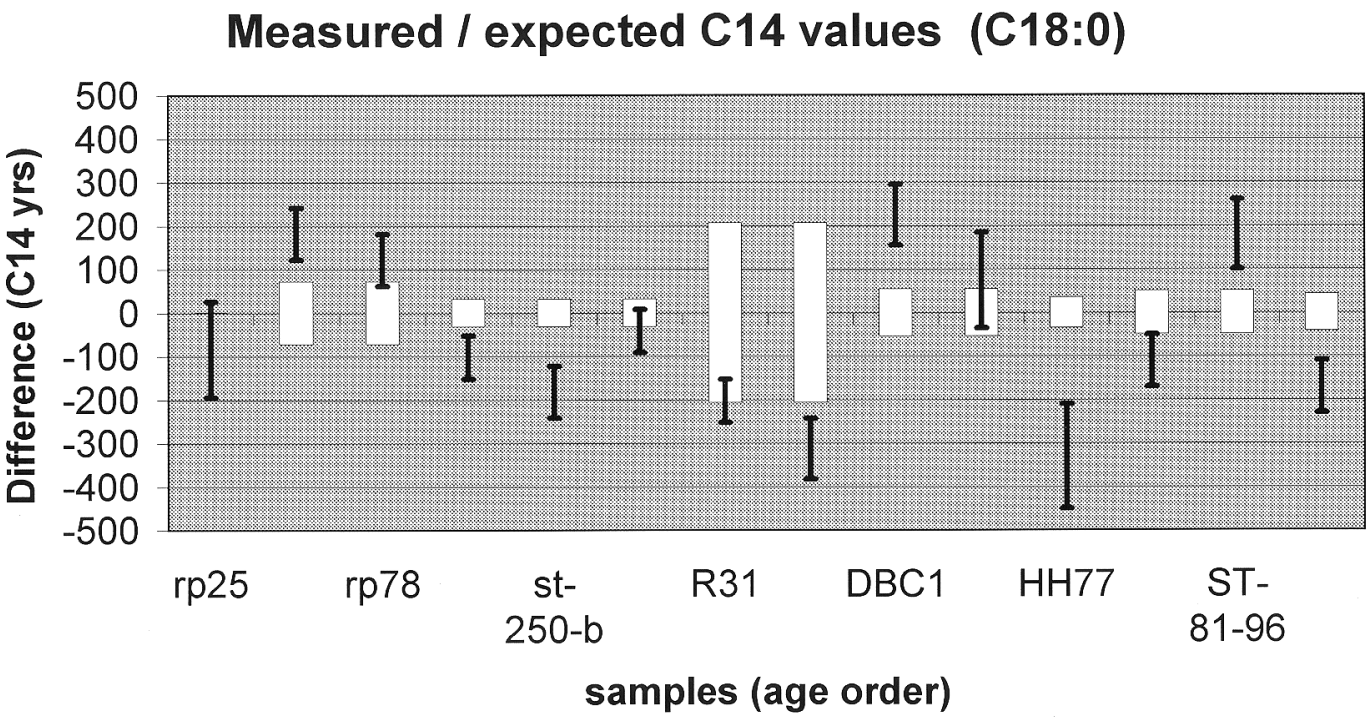

Figure 1 The difference (in ${ }^{14} \mathrm{C}$ years) between the measured ${ }^{14} \mathrm{C}$ age (on $\mathrm{C}_{18: 0}$ ) and the expected ${ }^{14} \mathrm{C}$ age for the individual potsherds. The samples are plotted in order of their archaeological age. The black bars represent the offset from the expected age and span \pm measurement error (one standard deviation). The white rectangles represent the estimated error in the expected age.

\section{MATERIAL}

Twelve sherds excavated from six English archaeological sites were studied. The sites range in age from about 1000 BP (Early Mediaeval [West Cotton]) to about 5000 BP (Early Neolithic [Hambledon Hill]). The expected age of each sherd is indicated in Table 1, and has been supplied by the archaeologist responsible for the excavation or the curation of material. In some cases (the earlier ones) this is based on ${ }^{14} \mathrm{C}$ dating of a close contextual association, in others on stylistic correlations to historical dates. Uncertainties in the expected age are a significant problem in testing the validity of the direct ${ }^{14} \mathrm{C}$ dates to the full limits of their quoted accuracy.

Potsherds from the six sites had already been studied for their lipid chemistry as part of a separate project. For this study, material containing $>300 \mu \mathrm{g} / \mathrm{g}$ of extractable lipid was selected. This necessitated pre-screening; for example, 20 sherds from Hambledon Hill were screened, 8 contained lipid, and 3 were chosen. As a test of replication, one sherd (of a Roman mortarium from Stanwick) was sampled separately three times. 


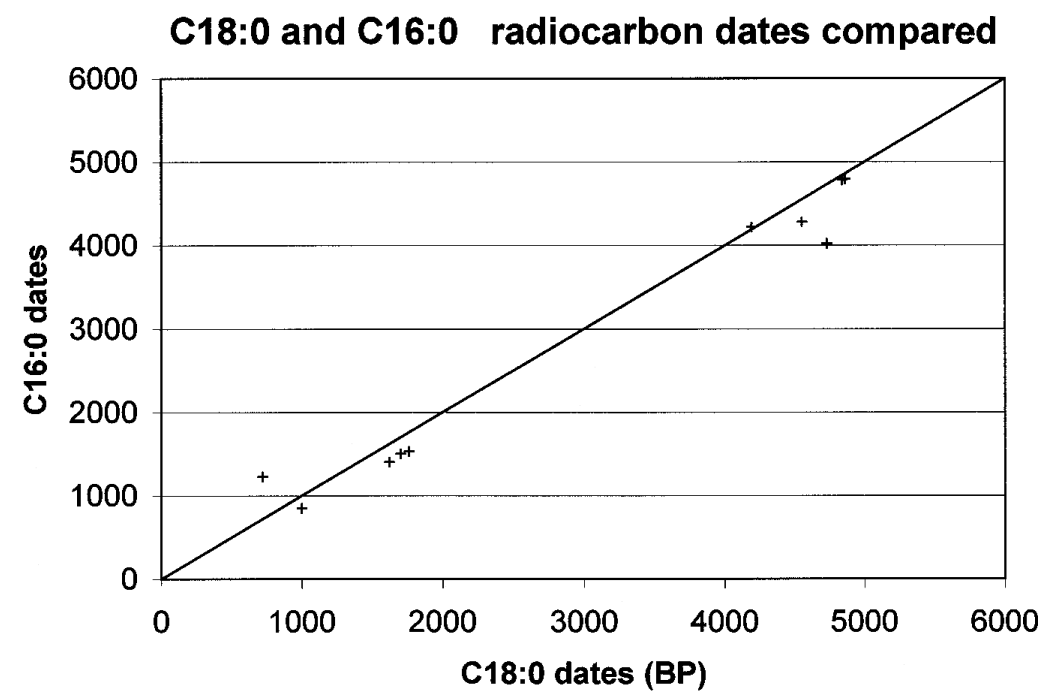

Figure 2 The radiocarbon date for $\mathrm{C}_{18: 0}$ plotted against that for $\mathrm{C}_{16: 0}$ where the same samples have been measured. Error bars are estimates of the error in the ${ }^{14} \mathrm{C}$ age measurement. The straight line corresponds to exact agreement.

The burial environments vary considerably between sites. Sweet Track has been continuously waterlogged and anoxic, Eton Rowing Lake has been intermittently submerged, West Cotton and Yarnton are on flood plains (usually sandy gravels), Hambledon Hill is upland chalk.

\section{METHOD}

A more detailed account of the methodology is to be presented in Stott et al. (forthcoming). The most salient features are described here.

About $8 \mathrm{~g}$ of powdered potsherd was extracted by Soxhlet with 2:1 v/v dichloromethane/methanol to produce a total lipid extract (TLE). Most of the TLE was hydrolyzed (methanolic $\mathrm{NaOH}$ ), acidified, extracted, and derivatized to fatty acid methyl esters (FAMES) in $2 \% \mathrm{v} / \mathrm{v}_{2} \mathrm{SO}_{4} / \mathrm{MeOH}$, and finally extracted into hexane. The remainder was analyzed by GC-MS and GC-C-IRMS after derivatizing with BSTFA (bis(trimethylsilyl)trifluoroacetamide).

Separation of the components, and in particular of the fatty acid methyl esters, from the derivatized TLE extract was achieved by repetitive operation of a microprocessor-controlled Hewlett Packard 5890 Series II gas chromatograph fitted with a "megabore" fused silica capillary column) (30 m $\times$ $0.53 \mathrm{~mm}$ i.d.) coated with dimethylpolysiloxane (DB-1, $0.5 \mu \mathrm{m}$ ). This was interfaced to a temperature $\left(250-300{ }^{\circ} \mathrm{C}\right)$ controlled preparative fraction collector with 6 capillary traps (at ambient temperature). About 100 runs were needed to accumulate the sample sizes required, with retention times being maintained to within 5 seconds over the whole set. The trapping efficiency was found to be $>90 \%$.

The fractions of purified fatty acid esters were transferred to a continuous-flow CHN analyzer (Europa-ANCA) combined with a stable isotope ratio mass spectrometer (Europa 20/20), fitted with $\mathrm{a} \mathrm{CO}_{2}$ collection facility (Hedges et al. 1992). The transfer was accomplished by dissolution in a few $\mu \mathrm{L}$ of hexane, which was loaded onto powdered tin contained in a standard tin capsule $(3.5 \times 5 \mathrm{~mm})$ which was placed inside a larger $(8 \times 5 \mathrm{~mm})$ tin capsule. This method avoided solvent creep while 
minimizing addition of extraneous carbon. Recoveries of $95 \%$ were demonstrated, using of 50 $200 \mu \mathrm{g}$ of material. The solvent was evaporated under a $\mathrm{N}_{2}$ stream at $40^{\circ} \mathrm{C}$. The quantities of carbon varied from $20 \mu \mathrm{g}$ to $1000 \mu \mathrm{g}$. The $\mathrm{CHN}$ analyzer uses $\mathrm{GC}$ to separate $\mathrm{CO}_{2}$ from other gases (though here only $\mathrm{H}_{2} \mathrm{O}$, which is trapped out, is produced during combustion), and the collected $\mathrm{CO}_{2}$ is used as the target material for the gas source (Bronk and Hedges 1987) of the AMS system (Bronk Ramsey and Hedges 1997). Analysis for dating is standard, but a correction must be made for the ${ }^{14} \mathrm{C} /{ }^{12} \mathrm{C}$ ratio of the additional methyl group added during derivatization. (Note that the correction will differ between $\mathrm{C}_{18: 0}$ and $\mathrm{C}_{16: 0}$ acids.) The AMS system actually measures the ${ }^{14} \mathrm{C} /{ }^{13} \mathrm{C}$ ratio, and allowance for the shift in $\delta^{13} \mathrm{C}$ of the sample with derivatization must be made.

\section{METHODOLOGICAL CONTROLS}

Several issues need to be established before meaningful dates can be obtained. These include:

1. Absence of ${ }^{14} \mathrm{C}$ radio-label contamination during chemical work-up (which may be undetectable at a purely chemical level),

2. Absence of contamination from solvents, etc.,

3. Chemical purity of separated chromatographic peaks. (For example, that any column bleed incorporated is negligible),

4. Introduction of significant carbon or ${ }^{14} \mathrm{C}$ during sample transfer from preparative $\mathrm{GC}$, and subsequent combustion.

The ${ }^{14} \mathrm{C}$ contents of the high purity solvents used were established to be negligible. As controls available for comparative bulk measurements, we used modern cocoa fatty acids, a $\mathrm{C}_{21}$ fatty acid standard (of about $60 \%$ modern ${ }^{14} \mathrm{C}$ ), and a petroleum-based $\mathrm{C}_{18} n$-alkane, all of which could be measured before and after preparative chromatography procedures. Sample sizes were matched to those of the archaeological samples. These showed that the quantity of "modern" carbon added in the total procedure (including combustion) was $<4 \mu \mathrm{g} \mathrm{C}$, and the quantity of "dead" carbon added in the total procedure was $<5 \mu \mathrm{g} \mathrm{C}$. This enables archaeological dates to be measured with final errors mainly dominated by counting statistics for samples up to a half-life old if they contain greater than $50 \mu \mathrm{g} \mathrm{C}$. (The correction applied for date calculation was $2.9 \pm 0.3 \mu \mathrm{g}$ modern carbon; this, and especially the variance, is provisional since the statistical distribution of background blanks has not been fully determined, but the effects on the dates are in any case small for most sample sizes.) Typically, samples of $>200 \mu \mathrm{g}$ are needed to achieve precisions of \pm 50 years or better.

We also made $\delta^{13} \mathrm{C}$ measurements on the fatty acids before and after collection, finding a small systematic decrease in ${ }^{13} \mathrm{C}$ content (by less than about $1 \%$ ). This has no significant effect on the radiocarbon date. Significant isotopic fractionation in the collection procedure is not a problem.

\section{RESULTS}

Not all sherds were measured for all $\mathrm{C}_{16: 0}, \mathrm{C}_{18: 0}, \mathrm{C}_{18: 1}$ components, though all except one were measured for $\mathrm{C}_{18: 0}$ as this was the most abundant compound present. The quantity of surviving material extracted varied greatly, and limited the precision when below $\sim 200 \mu \mathrm{g}$ of C, but in general, after corrections for carbon introduced during handling (established from the controls), typical errors of $\pm 50-60$ years can be estimated.

The Results are presented in Tables 1 and 2. A replication test was carried out on the Stanwick mortarium, which was sampled three times. It is seen that, within the errors quoted, the $\mathrm{C}_{18: 0}$ dates are 
consistent, and the $\mathrm{C}_{16: 0}$ dates are consistent, although there is a consistent difference between the two sets. This difference is discussed later.

${ }^{14} \mathrm{C}$ dates from the 15 sherds can be compared with the expected ${ }^{14} \mathrm{C}$ date. The latter have been evaluated either by a contextual association with other radiocarbon dates (most notably for Hambledon Hill), or by "de-calibrating" from a calendrical date range which is embedded in the archaeological chronology for the site or for the period defined by the pottery type. Where an "exact" date is indicated, for example the wooden track-way of Sweet Track is dendrochronologically dated to within a year, we have broadened this by \pm 50 years to take account of the chronological linkage based on stratigraphic association.

Table $1 \mathrm{C}_{18: 0}$ for $\mathrm{LH}$ column, $\mathrm{C}_{16: 0}$ for $\mathrm{RH}$ column, and where designated as $*, \mathrm{C}_{18: 1}$

\begin{tabular}{|c|c|c|c|c|c|c|c|}
\hline Sherd $^{\mathrm{a}}$ & Wt C $(\mu \mathrm{g})$ & Date & Error & Sherd & Wt C $(\mu \mathrm{g})$ & Date & Error \\
\hline & & & & rp22 & 29 & 500 & 150 \\
\hline \multirow[t]{2}{*}{$\operatorname{rp} 25$} & 293 & 720 & 60 & $\operatorname{rp} 25$ & 270 & 1230 & 60 \\
\hline & & & & *rp25 & 245 & 740 & 60 \\
\hline rp73 & 371 & 1060 & 50 & & & & \\
\hline \multirow[t]{2}{*}{ rp78 } & 416 & 1000 & 60 & $\operatorname{rp} 78$ & 79 & 850 & 50 \\
\hline & & & & *rp78 & 157 & 760 & 60 \\
\hline st-250-a & 489 & 1700 & 50 & st-250-a & 614 & 1500 & 50 \\
\hline st-250-b & 871 & 1620 & 40 & st-250-b & 552 & 1400 & 60 \\
\hline st-250-c & 615 & 1760 & 50 & st-250-c & 558 & 1530 & 70 \\
\hline R31 & 326 & 4300 & 110 & & & & \\
\hline \multirow[t]{2}{*}{ R5-9 } & 769 & 4190 & 70 & R5-9 & 599 & 4220 & 70 \\
\hline & & & & $* \mathrm{R} 5-9$ & 204 & 4100 & 110 \\
\hline DBC1 & 242 & 4730 & 80 & DBC1 & 104 & 4020 & 110 \\
\hline DBC-E & 280 & 4580 & 130 & & & & \\
\hline HH77 & 350 & 4540 & 80 & & & & \\
\hline ST-81-938 & 365 & 4550 & 90 & ST-81-938 & 442 & 4280 & 60 \\
\hline ST-81-96 & 794 & 4840 & 60 & ST-81-96 & 511 & 4780 & 60 \\
\hline Sw Trk 2 & 1081 & 4860 & 60 & Sw Trk 2 & 504 & 4790 & 60 \\
\hline
\end{tabular}

a Sites: $\mathrm{rp}=$ West Cotton; st = Stanwick; R = Yarnton; DBC = Eton Rowing Lake; HH and ST = Hambledon Hill;

Sw Trk $=$ Sweet Track

Table 2 Replicate extractions from one sherd: $\mathrm{C}_{18: 0}$ for $\mathrm{LH}$ column, $\mathrm{C}_{16: 0}$ for $\mathrm{RH}$ column

\begin{tabular}{lccccccc}
\hline & \multicolumn{3}{c}{$\mathrm{C}_{18: 0}$} & & \multicolumn{3}{c}{$\mathrm{C}_{16: 0}$} \\
\cline { 2 - 4 } \cline { 7 - 8 } Sherd & Wt C $(\mu \mathrm{g})$ & Date & Error & & Wt C $(\mu \mathrm{g})$ & Date & Error \\
\hline st-250-a & 489 & 1720 & 50 & & 614 & 1500 & 50 \\
st-250-b & 871 & 1640 & 40 & & 552 & 1400 & 60 \\
st-250-c & 615 & 1760 & 50 & & 558 & 1530 & 70 \\
\hline
\end{tabular}

\section{DISCUSSION}

The main issue is: how accurate are the radiocarbon dates measured by this approach? To some extent the limitations in precision of expected radiocarbon age of the material also limit the answer to this, as well as the fact that the population for which we have dates is still quite small. 
Nevertheless, the results show the following:

1. The average difference between the $\mathrm{C}_{18: 0}{ }^{14} \mathrm{C}$ age and the middle of the expected age for 14 of the 15 sherds is 54 years $\left({ }^{14} \mathrm{C}\right.$ age too young), but with a standard deviation of 183 years. The average difference between the $\mathrm{C}_{18: 0}{ }^{14} \mathrm{C}$ age and the nearest limit of the expected age for the 14 sherds is 25 years too young years, with a standard deviation of 123 years. There is no statistically significant correlation between direction and/or magnitude of the difference and archaeological age, neither is there any correlation of the difference with such methodological features as quantity of extracted fatty acid (admittedly the sample population is small).Therefore there seems to be no systematic error in $\mathrm{C}_{18: 0}$ dates throughout a 6000 -year range of potsherd use and burial. However, the variance in the date offset is larger, by a factor of two, than the estimated error.

2. The average difference between the $\mathrm{C}_{16: 0}$ radiocarbon age and the middle of the expected age for 11 sherds is -224 years, with a standard deviation of 260 years (or $-128 \pm 218$ taking the difference from the nearest limit). With a standard error of the population mean of 65 years, an offset of the mean of 224 years is statistically significant. The difference in date for each sherd (i.e. $\mathrm{DateC}_{18: 0}-\mathrm{DateC}_{16: 0}$ ), averaged over the population, is $-137 \pm 302$ years. The expected error for such a difference ought to be that of the combined radiocarbon measurements, i.e. 90 100 years per date pair difference, or $\sim 26$ years standard error for the population mean. $\mathrm{C}_{16: 0}$ dates are significantly younger (by 140 years on average) than $\mathrm{C}_{18: 0}$ dates, and also are significantly younger than the expected dates. The dates measured on $C_{18: 1}$ were in general close to the expected values, but only three were determined so results are not conclusive.

It is not clear to us why $\mathrm{C}_{18: 0}$ dates have a greater variability than the expected ${ }^{14} \mathrm{C}$ error. The dates made in triplicate do not show such variability, suggesting the issue is one of sample and context, rather than one of laboratory methodology. However, since environmental contamination is likely to be younger than the sample age, the variability does not have the pattern expected for this source. On the other hand, environmental contamination is a possible explanation for the $\mathrm{C}_{16: 0}$ dates; these can be expected to be more vulnerable to environmental contamination, since $\mathrm{C}_{16: 0}$ is more mobile than $\mathrm{C}_{18: 0}$ (being more soluble), and is present at a higher concentration than $\mathrm{C}_{18: 0}$ in soils, but less in potsherd lipids. If the average age of the environmental contaminant was half that of the potsherd, the average offset we find of 100-150 years would correspond to 4-5\% of external addition or mixing of soil $\mathrm{C}_{16: 0}$. But is difficult to estimate how realistic an explanation this is; local lipid concentrations within the potsherd are very much higher than the external concentration (by a factor of at least 10; Simpson et al. 1999). Also, the offset does not become larger for potsherds with lower concentrations of lipid, and it is not correlated with offsets in the $\mathrm{C}_{18: 0}$ date. Dating of the soil lipids surrounding the potsherd, and of the unhydrolized acyl glycerides extracted from the sherds would go much of the way to answering this issue.

\section{CONCLUSIONS}

We have developed and demonstrated a practical methodology for dating specific compounds (and octadecanoic or stearic acid- $\mathrm{C}_{18: 0}$-in particular) from the lipid material surviving in archaeological cooking pots. About $10 \mathrm{~g}$ of sherd is required, selected for a reasonably high lipid concentration. Throughout the 6000 year period studied, and over a variety of site environments within England, dates on $\mathrm{C}_{18: 0}$ show no apparent systematic error, but do have a greater variability than can be explained by the errors due to the separation chemistry and measurement process alone. This variability is as yet unexplained. Dates on $\mathrm{C}_{16: 0}$ show greater variability and a systematic error of 
approximately 100-150 years too young, and it is possible that this is due to contamination from the burial environment. Further work should clarify this.

The method clearly has potential for the accurate dating of pottery, but further improvements are necessary before it can be confidently used with the precision implied by the errors of the radiocarbon measurement. It is quite possible that samples smaller by a factor of 2 or 3 could be used, although the saving in sample size and preparation (especially GC) time is offset by the increasing sensitivity to carbon contamination.

\section{REFERENCES}

Bronk CR, Hedges REM. 1987. A gas ion source for radiocarbon dating. Nuclear Instruments and Methods in Physics Research B29:45-9.

Bronk Ramsey C, Hedges REM. 1997. Hybrid ion sources: radiocarbon measurements from microgram to milligram. Nuclear Instruments and Methods in Physics Research B 123:539-45.

Simpson, IA, van Gerben V, Perret VP, Elhmmali MM, Roberts DJ, Evershed RP. 1999. Lipid biomarkers as manuring practice in relict anthropogenic soils. Holocene 9(2):223-9.

Eglinton TI, Aluwihare LI, Bauer JE, Druffel ERM, McNichol AP. 1996. Gas chromatographic isolation of individual compounds from complex matrices for radiocarbon dating. Analytical Chemistry 68:904-12.

Evershed RP, Heron C, Charters S, Goad LJ. 1992. The survival of food residues: new methods of analysis, interpretation and application. Proceedings of the British Academy 77:187-208.

Evershed RP, Dudd SN, Charters S, Mottram H, Stott AW, Raven A, van Bergen PF, Bland HA. 1999. Lipids as carriers of anthropogenic signals from prehistory. Philosophical Transactions of the Royal Society B
354:19-31.

Evin J., Gabasio M, Lefevre J-C. 1989. Preparative techniques for radiocarbon dating of potsherds. Radiocarbon 31(3): 276.

Hedges REM, Humm MJ, Foreman J, Van Klinken GJ, Bronk CR. 1992. Developments in sample combustion to $\mathrm{CO} 2$, and in the $\mathrm{CO} 2$ ion source system. Radiocarbon 34(3):306-11.

Hedges REM, Tiemei, C, Housley RA 1992. Results and methods in the radiocarbon dating of pottery. Radiocarbon 34(3):906-15.

Johnson RA, Stipp JJ, Tamers MA, Bonani G, Suter M, Wolfli W. 1986. Archaeological sherd dating: comparison of thermoluminescence dates with radiocarbon dates by beta counting and accelerator techniques. $R a$ diocarbon 28(2A):719.

Kolic ED 1995. Direct radiocarbon dating of pottery: selective heat treatment to retrieve smoke-derived carbon. Radiocarbon, 37(2):275-84.

Stott AW, Berstan R, Evershed RP, Bronk-Ramsey C, Humm MJ, Hedges R. Forthcoming. Compound specific ${ }^{14} \mathrm{C}$ dating of lipids preserved in archaeological pottery. Analytical Chemistry. 